\title{
TRABALHO NOTURNO NA VIDA DOS ENFERMEIROS
}

\section{NIGHT WORK IN THE LIFE OF NURSES}

\author{
Alidne Pinheiro da Silva', Emilene Santos de Carvalho ${ }^{2}$, Adryanna Cardim ${ }^{3}$ \\ 'Graduada em Enfermagem na Universidade do Estado da Bahia. Especialista em Enfermagem do Trabalho pela Escola Bahiana de \\ Medicina e Saúde Pública. Salvador, Bahia, Brasil. http://orcid.org/0000-0001-7586-336X. alidne@hotmail.com \\ ${ }^{2}$ Graduada em Enfermagem na Faculdade São Salvador. Especialista em Enfermagem do Trabalho pela Escola Bahiana de Medicina e \\ Saúde Pública. Salvador, Bahia, Brasil. http://orcid.org/0000-0003-0882-9043. emilene82@yahoo.com.br \\ ${ }^{3}$ Doutoranda em Saúde Pública pelo Instituto de Saúde Coletiva/UFBA. Salvador, Bahia, Brasil. \\ http://orcid.org/0000-0002-5186-9481.adryanna@terra.com.br
}

RESUMO I O trabalho noturno na área da saúde é uma das formas de organizar o serviço de maneira a atender a demanda da população pelos serviços de saúde e prestar cuidado ininterrupto. Este ritmo de trabalho repercute diretamente na qualidade de vida destes profissionais. O objetivo geral desse trabalho é analisar as repercussões do trabalho noturno na vida dos enfermeiros. Trata-se de um estudo em caráter de revisão integrativa da literatura, pelo levantamento de 17 estudos publicados entre 2010 a 2016, em revistas indexadas nas bases de dados nacionais. Os dados foram analisados segundo a Análise de Conteúdo proposta por Bardin, assim emergiram três categorias: (01) implicações do trabalho noturno na saúde; (02) dificuldades do trabalho noturno na organização do trabalho; (03) repercussões do trabalho noturno na vida dos enfermeiros acerca das relações familiares em contrapartida aos aspectos positivos inerentes ao trabalho noturno destes profissionais. Os resultados apontam que 0 trabalho em turnos, principalmente no turno noturno, pode alterar algumas funções orgânicas nos indivíduos por alterar o ritmo do corpo humano. Os aspectos negativos relacionados com o trabalho noturno desenvolvido pelo enfermeiro envolvem as condições de que os funcionários do noturno sofrem um isolamento no que se refere a intercomunicação com outros setores, os quais não funcionam em esquema de plantão. $O$ enfermeiro do turno noturno sofre a dificuldade de manter o convívio social devido às implicações decorrentes do horário de trabalho, associadas à sonolência constante e irritabilidade. Por outro lado, identificou-se que ao trabalhar no período noturno, o enfermeiro lida com a questão de flexibilidade de horários, $\circ$ que the possibilita um duplo vínculo empregatício. Sendo assim conclui-se que é fundamental pensar em estratégias que possibilitem aos enfermeiros trabalhadores noturnos melhores condições de trabalho.

\begin{abstract}
The night shift in the health care sector is a way to organize the service in order to meet the population's demand for health services and to provide uninterrupted care. The general objective of this study is to analyze the repercussions of night work on nurses' lives. This type of work has a direct impact on the life quality of these professionals. This study is an integrative review of the literature, through the survey of 17 other studies published between 2010 and 2016, in journals indexed in the national databases. The data were analyzed according to the Content Analysis proposed by Bardin, thereby three categories emerged: $(01)$ overall health implications of the night shift; (02) difficulties regarding organization and (03) repercussions in familiar life as opposed to the positive aspects of the night shift. The results show that shift work, especially at night, can change some of the organic functions in individuals by altering the rhythm of the human body. One of the negative aspects related to the night work developed by nurses is that those workers suffer isolation when it comes to intercommunicate with other sectors, which do not work on shift schedule. The night shift nurse suffers from difficulty in maintaining social interaction due to the implications of the work schedule, associated to constant somnolence and irritability. On the other hand, it was identified that when working at night, these professionals have schedule flexibility, which makes possible a double employment relationship. Therefore, it can be concluded that it is fundamental to promote better working conditions to nurses that work in night shifts.
\end{abstract}

Keywords: night work, circadian rhythm, shift work, nurses.

Descritores: trabalho noturno, ritmo circadiano, trabalho em turnos, enfermeiros e enfermeiras. 


\section{INTRODUÇÃO}

O trabalho conserva um lugar importante na sociedade, considerado um fator fundamental para $\circ$ ser humano. A satisfação do trabalhador e sua produtividade constituem-se os principais indicadores de uma organização'.

A atividade profissional não se apresenta somente como uma forma de sustento, mas assim como uma maneira de inclusão social na qual aspecto psíquico e físico sofre grande influência ${ }^{2}$.

O trabalho noturno na área da saúde é uma das formas de organizar o serviço de maneira a atender a demanda da população pelos serviços de saúde e prestar cuidado ininterrupto. A escala de turno noturno possibilita ao trabalhador melhorar seus rendimentos através dos adicionais no salário, como também uma opção para aqueles colaboradores que necessitam de tempo livre para continuar os estudos, visando á melhoria na qualidade da assistência prestada, além da facilidade de intercalar o emprego noturno com um segundo emprego ${ }^{3}$.

Esta realidade é vivida por muitos trabalhadores principalmente os da área da saúde, o que implica no aumento da jornada de trabalho podendo comprometer o seu período de descanso e lazer. Este ritmo de trabalho repercute diretamente na sua qualidade de vida destes profissionais ${ }^{2}$ sendo considerado como um fator contribuinte de deterioração, envelhecimento e desenvolvimento de doenças graves ${ }^{4}$.

Com relação aos enfermeiros, que atualmente é a segunda categoria com maior número de profissionais inscritos com cerca de 446.119 registros ativos no Brasil $^{5}$, exercem sua função laboral principalmente em regime de escalas de plantões, ou seja, em turnos que incluem os finais de semana, horários noturnos e feriados ${ }^{6}$.

O trabalho noturno é visto também como um potencializador das repercussões físico e psíquico nos trabalhadores. A privação do sono e, às vezes, a impossibilidade de recuperá-lo na manhã seguinte após a jornada de trabalho noturna é apontada como os principais fatores de desgaste dos trabalhadores que executam suas atividades nesse turno ${ }^{7}$.
Um estudo realizado com 1940 enfermeiros, de 18 hospitais públicos, do Município do Rio de Janeiro demonstrou que 0 cochilo entre $\circ$ tempo de 2,1 a 3 horas durante o plantão noturno aumenta a chance de recuperação após o trabalho. Neste sentido evidencia a importância do cochilo como uma ferramenta associada à saúde do trabalhador e a qualidade da assistência prestada levando em consideração o caráter inevitável dos plantões noturnos em hospitais ${ }^{8}$.

Enfermeiros que trabalham em turno noturno, muitas vezes, não conseguem harmonizar a vida pessoal com a profissional e sofrem $\circ$ isolamento social em consequência do turno de trabalho ${ }^{3}$. No entanto, neste período, o processo de trabalho tem uma dinâmica diferenciada, sendo mais funcional e por isso, possibilita ao enfermeiro maior autonomia e tomada de decisões. Fato este que lhe confere maior aproximação com a equipe de trabalho sendo visto como um fator positivo ${ }^{4}$.

O interesse por essa temática percorre da observação acerca da atuação dos enfermeiros que desenvolvem suas atividades laborais no turno noturno. Entende-se que no trabalho noturno - enfermeiro precisa estar em constante estado de alerta para agir de forma rápida e eficaz na prestação da assistência ${ }^{8}$.

O objetivo deste estudo é analisar as repercussões do trabalho noturno na vida dos enfermeiros bem como, identificar as interferências que o trabalho noturno provoca na vida dos enfermeiros $e$ delinear os sintomas referentes ao estado geral de saúde associado ao trabalho noturno dos enfermeiros.

\section{MÉTODOS}

Trata-se de uma pesquisa bibliográfica, exploratória e descritiva. Através da pesquisa de revisão bibliográfica é possível reunir idéias oriundas de diversas fontes publicadas principalmente em forma de livros, revistas, 
publicações em periódicos e artigos científicos, jornais, boletins, entre outros?

Foram levantados artigos originais publicados no período entre 2010 a 2016, que estavam disponíveis na íntegra, on-line e gratuitos, publicados nos idiomas português, inglês e espanhol, e que responderam a questão norteadora deste estudo.

As dissertações, teses e trabalhos de congressos, artigos repetidos ou cuja temática do trabalho noturno não envolva a equipe de enfermagem, além dos estudos que apresentaram na metodologia artigos de revisão de literatura foram excluídos do estudo.

A pesquisa foi realizada a partir de levantamento nas bases de dados das bibliotecas virtuais LILACS (Literatura Latino-Americana e do Caribe em Ciências da Saúde), SCIELO Brasil (Scientific Eletronic Library Online), Biblioteca Virtual em Saúde (BVS), Base de Dados de Enfermagem (BDENF), Medical Literature Analysisand Retrieval System Online (MEDLINE). Esta busca nas bases de dados ocorreu no período de setembro a outubro de 2016 .

A apreciação dos dados ocorreu segundo a Análise de Conteúdo proposta por Bardin, por meio de exploração do material e tratamento e interpretação dos resultados. Realizou-se uma leitura na íntegra dos estudos, seguida da elaboração de quadros sintéticos com as variáveis: ano de publicação, título, objetivo do estudo, tipo de sujeitos, e principais resultados relacionados aos fatores positivos e fatores negativos do trabalho noturno. Após organização dos dados, foram feitas interpretações dos resultados e conferência se os mesmos respondiam a questão norteadora do estudo.

Desse modo, emergiram três categorias responsáveis por apresentar a síntese dos dados coletados e permitir uma análise à luz da literatura atual sobre - tema. Na primeira categoria (01) discutiu-se o trabalho noturno e suas implicações no estado geral de saúde do enfermeiro. A segunda categoria (02) apresentou as dificuldades do trabalho noturno na organização do trabalho para o enfermeiro. $\mathrm{Na}$ terceira categoria (03) debateram-se as repercussões do trabalho noturno na vida dos enfermeiros a cerca das relações familiares em contrapartida aos aspectos positivos inerentes ao trabalho noturno destes profissionais.

projeto não foi submetido a Comitê de Ética em Pesquisa por se tratar de artigo de revisão bibliográfica, respeitando e cumprindo as exigências setoriais e regulamentações específicas, em conformidade com os dispositivos legais da resolução 466/12.

\section{RESULTADOS E DISCUSSÃO}

No total, foram encontrados 24 artigos LILACS, 11 artigos SCIELO, 11 artigos BDENF e 235 artigos MEDLINE. Após leitura dos resumos sobraram 4 artigos LILACS, 5 artigos SCIELO, 65 artigos MEDLNE e os artigos BDENF foram descartados por estarem repetidos em outras bases de dados já utilizadas. Depois da leitura na íntegra, foram utilizados 3 artigos SCIELO, 7 artigos MEDLINE e nenhum artigo LILACS, (Tabela 1)

Tabela 1. xxxxxx

\begin{tabular}{|c|c|c|c|c|c|}
\hline TíTULO & AUTOR(ES) & ANO & OBJETIVO DO ESTUDO & TIPO DE SUJEITOS & PRINCIPAIS RESULTADOS \\
\hline $\begin{array}{l}\text { Association of salivary cortisol } \\
\text { with chronomics of } 24 \text { hours } \\
\text { ambulatory blood } \\
\text { pressure/heart rate among } \\
\text { night shift workers. }\end{array}$ & $\begin{array}{l}\text { ANJUM, Baby; } \\
\text { VERMA, Nar Singh; } \\
\text { TIWARI, Sandeep; } \\
\text { SINGH, Ranjana; } \\
\text { MAHDI, Abbas A.; } \\
\text { SINGH, Ram B.; } \\
\text { SINGH, Raj K }\end{array}$ & 2011 & $\begin{array}{l}\text { Avaliar a natureza } \\
\text { circadiana da pressão } \\
\text { arterial, freqüência } \\
\text { cardíaca e cortisol salivar } \\
\text { em trabalhadores de turno } \\
\text { da noite, para descobrir se } \\
\text { há uma relação entre o } \\
\text { ritmo circadiano da pressão } \\
\text { arterial, freqüência } \\
\text { cardiaca e níveis de cortisol } \\
\text { salivar e se essas alterações } \\
\text { são reversíveis após a } \\
\text { mudança nos horários de } \\
\text { serviço }\end{array}$ & $\begin{array}{l}\text { Profissionais de } \\
\text { enfermagem saudáveis } \\
\text { e saudáveis com idade } \\
\text { entre } 20 \text { e } 40 \text { anos, } \\
\text { realizando tarefas } \\
\text { diurnas e noturnas } \\
\text { (turnos noturnos } \\
\text { contínuos de } 9 \text { dias com } \\
\text { turnos diários } \\
\text { alternados) por } 8 \text { anos }\end{array}$ & $\begin{array}{l}\text { Houve alterações } \\
\text { clinicamente significativas } \\
\text { no momento em que ocorre } \\
\text { o pico de pressão arterial } \\
\text { e niveis de cortisol. } \\
\text { Alterações na amplitude } \\
\text { dupla foram observadas } \\
\text { em } 8 \text { individuos durante } \\
\text { turnos noturnos, bem como } \\
\text { em } 7 \text { individuos durante } \\
\text { turnos diurnos. }\end{array}$ \\
\hline
\end{tabular}


Tabela 1. xxxxxx (continuação)

\begin{tabular}{|c|c|c|c|c|c|}
\hline TítULO & AUTOR(ES) & ANO & OBJETIVO DO ESTUDO & TIPO DE SUJEITOS & PRINCIPAIS RESULTADOS \\
\hline \multirow[t]{2}{*}{$\begin{array}{l}\text { Factors associated with shift } \\
\text { work disorder in nurses } \\
\text { working with rapid-rotation } \\
\text { schedules in Japan: the nurses' } \\
\text { sleep health project. }\end{array}$} & $\begin{array}{l}\text { ASAOKA, Shoichi; } \\
\text { ARITAKE, Sayaka; } \\
\text { KOMADA, Yoko; } \\
\text { OZAKI, Akiko; } \\
\text { ODAGIRI, Yuko; INOUE, } \\
\text { Shigeru; SHIMOMITSU, } \\
\text { Teruichi; } \\
\text { INOUE, Yuichi. }\end{array}$ & 2013 & $\begin{array}{l}\text { Conhecer o impacto de ter } \\
\text { SWD (transtorno de } \\
\text { trabalho por turnos) em } \\
\text { trabalhadores por turnos } \\
\text { engajados em horários de } \\
\text { rotação rápida e os fatores } \\
\text { de risco para a sua } \\
\text { ocorrência. }\end{array}$ & $\begin{array}{l}1202 \text { enfermeiras que } \\
\text { trabalhavam em } \\
\text { hospitais universitários } \\
\text { em Tóquio, no Japão, } \\
\text { incluindo } 727 \\
\text { trabalhadores de dois } \\
\text { turnos e } 315 \\
\text { trabalhadores de três } \\
\text { turnos. }\end{array}$ & $\begin{array}{l}\text { Os enfermeiros de turno } \\
\text { com SWD apresentaram } \\
\text { menor qualidade de vida } \\
\text { relacionada à saúde e } \\
\text { sintomas depressivos mais } \\
\text { graves, com maiores taxas } \\
\text { de acidentes reais / erros } \\
\text { do que aqueles sem SWD. } \\
\text { A ausência de } \\
\text { oportunidades de soneca } \\
\text { durante o trabalho }\end{array}$ \\
\hline & & & & & $\begin{array}{l}\text { noturno, longas horas } \\
\text { noturnas de trabalho e o } \\
\text { atraso dos ritmos } \\
\text { circadianos estão } \\
\text { associados com a } \\
\text { ocorrência de SWD entre } \\
\text { enfermeiros de turno em } \\
\text { horários de rotação } \\
\text { rápida }\end{array}$ \\
\hline $\begin{array}{l}\text { Association of } 12 \mathrm{~h} \text { shifts and } \\
\text { nurses' job satisfaction, } \\
\text { burnout and intention to } \\
\text { leave: findings from a cross- } \\
\text { sectional study of } 12 \\
\text { European countries. }\end{array}$ & $\begin{array}{l}\text { DALL'ORA, Chiara; } \\
\text { GRIFFITHS, Peter; BALL, } \\
\text { Jane; } \\
\text { SIMON, Michael; } \\
\text { AIKEN, Linda H. }\end{array}$ & 2015 & $\begin{array}{l}\text { Examinar a associação entre } \\
\text { o trabalho em turnos longos } \\
\text { e o burnout, a insatisfação } \\
\text { no trabalho, a flexibilidade } \\
\text { do horário de trabalho e a } \\
\text { intenção de deixar o } \\
\text { trabalho atual entre os } \\
\text { enfermeiros do hospital. }\end{array}$ & $\begin{array}{l}31627 \text { enfermeiros em } \\
2170 \text { unidades médicas } \\
\text { / cirúrgicas gerais em } \\
488 \text { hospitais em } 12 \\
\text { países europeus }\end{array}$ & $\begin{array}{l}\text { As enfermeiras com turnos } \\
\text { de } \geq 12 \text { h apresentaram } \\
\text { maior probabilidade de } \\
\text { sofrer burnout em termos } \\
\text { de exaustão emocional do } \\
\text { que os enfermeiros que } \\
\text { trabalhavam menos horas, } \\
\text { despersonalização e baixa } \\
\text { realização pessoal. } \\
\text { As enfermeiras com turnos } \\
\text { de } \geq 12 \text { h apresentaram } \\
\text { maior probabilidade de } \\
\text { ter insatisfação com o } \\
\text { trabalho, insatisfação com } \\
\text { a flexibilidade do horário } \\
\text { de trabalho e intenção de } \\
\text { deixar o trabalho devido } \\
\text { á insatisfação. }\end{array}$ \\
\hline \multirow[t]{2}{*}{$\begin{array}{l}\text { Percepção do enfermeiro } \\
\text { sobre os efeitos do trabalho } \\
\text { noturno em sua vida }\end{array}$} & $\begin{array}{l}\text { GIRONDI, Juliana } \\
\text { Balbirot Reis; } \\
\text { GELBECKE, Francine } \\
\text { Lima }\end{array}$ & 2011 & $\begin{array}{l}\text { Identificar as percepções } \\
\text { dos enfermeiros de um } \\
\text { hospital universitário do sul } \\
\text { do país acerca dos efeitos }\end{array}$ & $\begin{array}{l}\text { Enfermeiros não } \\
\text { ocupantes de cargo de } \\
\text { chefia, que } \\
\text { desempenham seu }\end{array}$ & $\begin{array}{l}\text { O trabalho afeta } \\
\text { diretamente o equilíbrio } \\
\text { psíquico do trabalhador, } \\
\text { uma vez que não há como }\end{array}$ \\
\hline & & & $\begin{array}{l}\text { do trabalho noturno sobre a } \\
\text { saúde e vida social }\end{array}$ & $\begin{array}{l}\text { trabalho há mais de um } \\
\text { ano no periodo noturno } \\
\text { e que concordaram em } \\
\text { participar do estudo }\end{array}$ & $\begin{array}{l}\text { dissociar a saúde } \\
\text { psicológica da física, e por } \\
\text { isso o trabalho noturno } \\
\text { demanda uma } \\
\text { reformulação geral de } \\
\text { hábitos de vida. } \\
\text { Qualidade do sono } \\
\text { prejudicada, atividades de } \\
\text { educação em saúde } \\
\text { restritas, cansaço físico e } \\
\text { mental. }\end{array}$ \\
\hline $\begin{array}{l}\text { Do psychosocial factors } \\
\text { moderate the association of } \\
\text { fixed-term employment with } \\
\text { work interference with family } \\
\text { and sleeping problems in } \\
\text { registered nurses: a cross- } \\
\text { sectional questionnaire survey. }\end{array}$ & $\begin{array}{l}\text { HEPONIEMI, Taria; } \\
\text { KOUVONEN, Anne; } \\
\text { SINERVO, Timo; } \\
\text { ELOVAINIO, Marko; }\end{array}$ & 2010 & $\begin{array}{l}\text { Examinar a associação do } \\
\text { tipo de emprego com a } \\
\text { interferência do trabalho } \\
\text { com a família (WIF) e } \\
\text { problemas de sono. Além } \\
\text { disso, examinar se a justiça } \\
\text { organizacional e o controle } \\
\text { do trabalho foram capazes } \\
\text { de moderar associações } \\
\text { mencionadas. }\end{array}$ & $\begin{array}{l}1767 \text { enfermeiros } \\
\text { finlandeses registrados } \\
\text { ( } 1676 \text { mulheres e } 91 \\
\text { homens) com idade } \\
\text { entre } 23-60 \text { anos }\end{array}$ & $\begin{array}{l}\text { A justiça organizacional } \\
\text { moderou a associação } \\
\text { entre tipo de emprego e } \\
\text { WIF. } \\
\text { Niveis elevados de justiça } \\
\text { estavam diretamente } \\
\text { associados a menos WIF e } \\
\text { menos problemas de sono, } \\
\text { e altos niveis de controle } \\
\text { de trabalho com menos } \\
\text { problemas de sono. }\end{array}$ \\
\hline $\begin{array}{l}\text { Trabalho noturno e a } \\
\text { repercussão na saúde dos } \\
\text { enfermeiros }\end{array}$ & $\begin{array}{l}\text { SILVA, Rosângela } \\
\text { Marion da., } \\
\text { BECK, Carmem Lúcia } \\
\text { Colomé, } \\
\text { MAGNAGO, Tânia }\end{array}$ & 2011 & $\begin{array}{l}\text { Apresentar e discutir as } \\
\text { alterações na saúde } \\
\text { percebidas por enfermeiros } \\
\text { de um Hospital } \\
\text { Universitário decorrente da }\end{array}$ & $\begin{array}{l}42 \text { enfermeiros do } \\
\text { Hospital Universitário } \\
\text { de Santa Maria, } \\
\text { hospital-escola Porte IV } \\
\text { localizado na Região } \\
\text { Sul do Brasil. }\end{array}$ & $\begin{array}{l}27 \text { enfermeiros percebem } \\
\text { alterações na saúde como } \\
\text { a má qualidade no } \\
\text { sono/repouso, o } \\
\text { cansaço/desgaste, } \\
\text { isolamento, entre outras. }\end{array}$ \\
\hline
\end{tabular}


Tabela 1. xxxxxx (continuação)

\begin{tabular}{|c|c|c|c|c|c|}
\hline TítULO & AUTOR(ES) & ANO & OBJETIVO DO ESTUDO & TIPO DE SUJEITOS & PRINCIPAIS RESULTADOS \\
\hline & $\begin{array}{l}\text { CARMAGNANI, Maria } \\
\text { Isabel Sampaio, } \\
\text { TAVARES, Juliana Petri, } \\
\text { PRESTES, Francine } \\
\text { Cassol }\end{array}$ & & periodo noturno. & & $\begin{array}{l}\text { trabalhar no periodo } \\
\text { noturno para continuar os } \\
\text { estudos ou a possibilidade } \\
\text { de conciliar o segundo } \\
\text { emprego }\end{array}$ \\
\hline $\begin{array}{l}\text { Nurses' work schedule } \\
\text { characteristic, nurse staffing, } \\
\text { and patient mortality. }\end{array}$ & $\begin{array}{l}\text { TRINKOFF, Alison M.; } \\
\text { JOHANTGEN, Meg; } \\
\text { STORR, Carla L.; } \\
\text { GURSES, Ayse P.; } \\
\text { LIANG, Yulan; } \\
\text { HAN, Kihye }\end{array}$ & 2011 & $\begin{array}{l}\text { Determinar se, em hospitais } \\
\text { onde os enfermeiros relatam } \\
\text { horários de trabalho mais } \\
\text { adversos, haveria aumento } \\
\text { da mortalidade dos } \\
\text { pacientes, controlando o } \\
\text { pessoal. }\end{array}$ & $\begin{array}{l}\text { Enfermeiros que } \\
\text { trabalham em } 71 \\
\text { hospitais não-federais } \\
\text { agudos na Carolina do } \\
\text { Norte e Illinois }\end{array}$ & $\begin{array}{l}\text { O horário de trabalho } \\
\text { relacionou-se } \\
\text { significativamente com a } \\
\text { mortalidade quando os } \\
\text { niveis de pessoal e as } \\
\text { características hospitalares } \\
\text { foram controladas } \\
\text { As mortes por pneumonia, } \\
\text { aneurisma da aorta } \\
\text { abdominal foram } \\
\text { significativamente mais } \\
\text { prováveis nos hospitais } \\
\text { onde os enfermeiros } \\
\text { relataram horários com } \\
\text { longas horas de trabalho. } \\
\text { Para pacientes com } \\
\text { insuficiência cardíaca } \\
\text { congestiva, a mortalidade } \\
\text { foi associada ao trabalho } \\
\text { enquanto doente. }\end{array}$ \\
\hline & & & & & Infarto agudo do \\
\hline & & & & & $\begin{array}{l}\text { miocárdio foi associado } \\
\text { significativamente com } 0 \\
\text { fardo semanal das } \\
\text { enfermeiras. }\end{array}$ \\
\hline $\begin{array}{l}\text { Factors and symptoms } \\
\text { associated with work stress } \\
\text { and health-promoting } \\
\text { lifestyles among hospital staff: } \\
\text { a pilot study in Taiwan. }\end{array}$ & $\begin{array}{l}\text { TSAI, Yueh-Chi; } \\
\text { LIU, Chieh-Hsing. }\end{array}$ & 2012 & $\begin{array}{l}\text { Investigar fatores associados } \\
\text { ao estresse no trabalho } \\
\text { entre os funcionários do } \\
\text { hospital e avaliar seus } \\
\text { comportamentos de estilo de } \\
\text { vida que promovem a saúde }\end{array}$ & $\begin{array}{l}\text { Profissionais de dois } \\
\text { hospitais regionais }\end{array}$ & $\begin{array}{l}\text { Os sintomas auto-relatados } \\
\text { de estresse relacionado ao } \\
\text { trabalho incluiram } 64,4 \% \\
\text { dos individuos relatando } \\
\text { nervosismo, } 33,7 \% \\
\text { pesadelos, } 44,1 \% \\
\text { irritabilidade, } 40,8 \% \\
\text { dores de cabeça, } 35,0 \% \\
\text { insônia e } 41,4 \% \text { surtos } \\
\text { gastrointestinais. }\end{array}$ \\
\hline $\begin{array}{l}\text { Estresse ocupacional: } \\
\text { Avaliação de enfermeiros } \\
\text { intensivistas que atuam no } \\
\text { período noturno }\end{array}$ & $\begin{array}{l}\text { VERSA, Gelena Lucinéia } \\
\text { Gomes da Silva, } \\
\text { MURASSAKI, Ana } \\
\text { Claudia Yassuko } \\
\text { INOUE, Kelly Cristina, } \\
\text { MELO, Willian Augusto } \\
\text { de, FALLER, Jossiana } \\
\text { Wilke, } \\
\text { MATSUDA, Laura Misue. }\end{array}$ & 2012 & $\begin{array}{l}\text { Avaliar o nível de estresse } \\
\text { de enfermeiros } \\
\text { intensivistas do periodo } \\
\text { noturno }\end{array}$ & $\begin{array}{l}\text { Enfermeiros intensivistas } \\
\text { atuantes no periodo } \\
\text { noturno, em UTI-Adulto, } \\
\text { UTI-Pediátrica e UTI- } \\
\text { Neonatal de cinco } \\
\text { instituições hospitalares } \\
\text { da região Oeste do } \\
\text { Estado do Paraná. } \\
\text { Dentre os cinco } \\
\text { hospitais, quatro são } \\
\text { privados e um é } \\
\text { público. }\end{array}$ & $\begin{array}{l}\text { Os domínios que mais } \\
\text { contribuíram ao } \\
\text { acontecimento de estresse } \\
\text { foram: condições de } \\
\text { trabalho (labor noturno, } \\
\text { setor crítico e fechado), } \\
\text { gravidade do paciente e } \\
\text { atividades gerenciais } \\
\text { associadas à assistência } \\
\text { direta. }\end{array}$ \\
\hline \multirow[t]{2}{*}{$\begin{array}{l}\text { Aspectos cronobiológicos do } \\
\text { sono de enfermeiras de um } \\
\text { hospital universitário }\end{array}$} & $\begin{array}{l}\text { XAVIER, Karine } \\
\text { Gracinda da Silva, } \\
\text { VAGUETTI, Helena }\end{array}$ & 2012 & $\begin{array}{l}\text { Identificar o cronotipo } \\
\text { das enfermeiras dos turnos } \\
\text { da manha e da noite de um }\end{array}$ & $\begin{array}{l}15 \text { enfermeiras, } 7 \text { do } \\
\text { turno matutino e } 8 \text { do } \\
\text { turno noturno de um }\end{array}$ & $\begin{array}{l}\text { Cinco enfermeiras } \\
\text { moderadamente matutinas, } \\
\text { quatro indiferentes, duas }\end{array}$ \\
\hline & Heidtmann. & & $\begin{array}{l}\text { hospital universitario; } \\
\text { verificar como o trabalho } \\
\text { nos turnos da manha e da } \\
\text { noite influencia o sono das } \\
\text { mesmas; correlacionar } \\
\text { o cronotipo das enfermeiras } \\
\text { com as influencias que o } \\
\text { sono ou a falta deste } \\
\text { produz em seu trabalho e } \\
\text { fora dele }\end{array}$ & $\begin{array}{l}\text { hospital universitário do } \\
\text { sul do Brasil }\end{array}$ & $\begin{array}{l}\text { moderadamente } \\
\text { vespertinas, três } \\
\text { definitivamente vespertinas } \\
\text { e uma definitivamente } \\
\text { matutina. } \\
\text { O trabalho em turnos faz } \\
\text { com que as entrevistadas } \\
\text { desenvolvam hábitos } \\
\text { alimentares e de sono, } \\
\text { peculiares. }\end{array}$ \\
\hline
\end{tabular}




\section{O TRABALHO NOTURNO E SUAS IMPLICAÇÕES NO ESTADO GERAL DE SAÚDE DO ENFERMEIRO}

O trabalho em turnos, principalmente no turno noturno, pode alterar algumas funções orgânicas nos indivíduos por alterar o ritmo do corpo humano. Eventos bioquímicos, fisiológicos e comportamentais funcionam de forma diferente dependendo do indivíduo estar acordado ou dormindo e essa seqüência natural que os prepara para o sono e para acordar é afetada por permanecerem acordados durante a noite ou levantarem cedo pela manhã ${ }^{10}$.

Neste sentido, o ritmo circadiano é completamente modificado, já que o corpo humano funciona como um relógio sincronizado, a inversão dos horários de acordar, dormir, alimentar-se repercute diretamente na saúde do trabalhador. Uma anormalidade no ritmo circadiano pode significar irritabilidade, estresse, fadiga, mal-estar geral, má-qualidade no serviço prestado, além de alterações nas funções orgânicas do corpo.

O padrão sono-vigília dos enfermeiros, freqüentemente é afetado, pois os mesmos trabalham contra o relógio biológico interno, podendo vir a sofrer de sonolência, comprometendo sua segurança e a prática clínica de qualidade, sendo importante a prevenção e o tratamento do transtorno de trabalho por turnos ${ }^{11}$.

O trabalho noturno acarreta alterações na saúde do trabalhador uma vez que há a inversão do ciclo sono-vigília, pois no momento em que o organismo se prepara para $\circ$ descanso, 0 trabalhador está realizando suas atividades ${ }^{3}$.

Em um estudo descritivo e exploratório realizado com 42 enfermeiros, $57,14 \%$ relataram alterações na saúde, uma ou mais alterações físicas, psíquicas e fisiológicas decorrentes do trabalho noturno. Foram identificados relatos de cansaço/desgaste, máqualidade no sono/repouso, ganho ponderal, malestar gástrico entre outros sinais e sintomas que pode comprometer a qualidade de vida dos mesmos ${ }^{3}$.

O sono é uma necessidade humana básica e sua ausência produz cansaço além de poder causar outros sintomas, como a irritabilidade e a intolerância, sintomas que podem ser prejudiciais ao trabalho das enfermeiras, impactando diretamente na sua qualidade de vida no trabalho ${ }^{10}$.

Em uma pesquisa com 16 enfermeiros saudáveis, que trabalhavam em períodos noturnos, a maioria relatou sentir cansaço após o trabalho, pois precisavam estar acordados quando deveriam estar dormindo, alterando o ciclo circadiano normal, podendo ter impactos na saúde, no desempenho e na segurança dos mesmos e dos pacientes. A maioria das queixas foi de dor de cabeça, fadiga, sonolência e dificuldade em adormecer ${ }^{12}$.

A privação do sono reduz o estado de alerta e a atenção do trabalhador, o sono acumulado diminui a capacidade mental comprometendo a assistência prestada, bem como o cansaço físico, que foi relatado pela maioria dos trabalhadores ${ }^{3}$.

Fato que vai representar queda significativa no desempenho funcional do enfermeiro noturno, assim como o aumento do risco de acidentes no trabalho e até mesmo fora dele. Por vezes, esse trabalhador perpassa pela dificuldade de recuperar $\circ$ sono no dia seguinte após o trabalho noturno, visto que existem outras demandas de cunho pessoal para administrar.

Estudo realizado com 633 enfermeiros que trabalhavam em 71 hospitais não-federais na Carolina do Norte e Illinois demonstrou que quase metade dos participantes trabalhou horas adicionais e essa falta de tempo para o descanso e recuperação poderia afetar a saúde e desempenho dos profissionais, visto que limitava a capacidade destes em detectar alterações nos doentes e responder a elas em tempo hábilil ${ }^{13}$.

Visto que o corpo necessita de um período de descanso para um bom funcionamento, o enfermeiro que trabalha no turno noturno sofre, tanto com as repercussões negativas no seu estado geral de saúde decorrentes do turno de trabalho, devido principalmente a inversão do ciclo circadiano, quanto á assistência por ele prestada aos clientes decai em qualidade e maior probabilidade de incidir erros.

\section{AS DIFICULDADES RECORRENTES DO TRABALHO NOTURNO NA ORGANIZAÇÃO DO SERVIÇO PELO ENFERMEIRO}


No hospital, a presença do enfermeiro é solicitada constantemente e não há horário para as intercorrências. Os enfermeiros necessitam estar acordados para prestar assistência em um momento em que seus níveis fisiológicos, de vigilância e de eficiência estão baixos podendo comprometer a qualidade na assistência ${ }^{10}$.

O contato direto dos profissionais do período noturno com os outros membros da equipe é dificultado gerando estresse ocupacional. Essa pode ser uma das principais causas do mesmo, prejudicando a tomada de decisões do enfermeiro terminando por comprometer o cuidado prestado pela falta e/ou falhas na comunicação' ${ }^{14}$.

Mesmo que os hospitais tenham como característica principal a prestação do cuidado ininterrupto 24 horas por dia, existem setores do estabelecimento de saúde que não acompanham esse funcionamento no período noturno, o que dificulta a organização e $\circ$ andamento na prestação do cuidado oferecido pelo enfermeiro de plantão.

Em um estudo piloto sobre fatores e sintomas associados ao estresse no trabalho e a promoção da saúde entre funcionários de um hospital realizado com 775 pessoas das quais 376 eram enfermeiros $(48,5 \%)$, revelou que estes apresentaram menos desempenho na categoria de auto-realização, sentindo-se sem apoio dos colegas de trabalho e supervisores valorizando as relações de trabalho ${ }^{15}$.

Muitas vezes no período noturno o enfermeiro designado para a função sofre uma sobrecarga de trabalho exaustiva tanto pelo quantitativo de funcionários reduzido quanto pela responsabilidade na tomada de decisões ser maior devido a ausência de uma chefia imediata nesse turno de trabalho.

Um estudo com 31627 enfermeiros de 2170 unidades médicas/cirúrgicas gerais de 488 hospitais em 12 países europeus demonstrou que os enfermeiros que haviam trabalhado 12 horas ou mais em seu ultimo turno tinham mais probabilidade de experimentar exaustão emocional se comparados á aqueles que trabalharam 8 horas ou menos 16 .

Os aspectos negativos relacionados com o trabalho noturno desenvolvido pelo enfermeiro envolvem as condições de que os funcionários do noturno sofrem um isolamento no que se refere a intercomunicação com outros setores, os quais não funcionam em esquema de plantão. Outra questão a ser mencionada é a dificuldades de trabalho com alguns plantonistas médicos. Assim constituem variáveis que refletem diretamente na qualidade da assistência prestada ${ }^{4}$.

O trabalho noturno exige do enfermeiro maior estado de alerta e atenção, porém vai de encontro às necessidades inerentes ao ser humano. Turnos de trabalho mais longos e em horários contrários ao ciclo circadiano implica em um menor tempo de descanso, fadiga excessiva e questões que refletem diretamente na qualidade do serviço prestado, envolvendo o ambiente de trabalho.

\section{AS REPERCUSSÕES DO TRABALHO NOTURNO} NA VIDA DOS ENFERMEIROS A CERCA DAS RELAÇÕES FAMILIARES E OS ASPECTOS POSITIVOS PROVENIENTES DO SERVIÇO NOTURNO.

Um estudo com 1767 enfermeiros finlandeses registrados demonstrou que trabalhadores mais velhos com horas extras e com menor percepção de justiça organizacional e de controle de trabalho eram mais propensos a interferência do trabalho nos problemas familiares e de sono quando comparados a aqueles que tinham altos níveis de justiça, os trabalhadores com contrato de duração determinada também referiram interferência do trabalho na sua vida familiar ${ }^{17}$.

Pelo fato da maioria das pessoas trabalharem durante $\circ$ dia e saírem a noite, os trabalhadores do período noturno têm dificuldade de manter suas relações familiares e sociais, fazendo com que os mesmos tenham a sensação de isolamento ${ }^{3}$.

Constatando que talvez em organizações justas, o empregado por não terem a obrigação de aceitar trabalho às custas da vida familiar elimina ou diminui grande parte do desconforto gerado pela incerteza das oportunidades de emprego futuro ${ }^{17}$.

O enfermeiro do turno noturno sofre a dificuldade de manter o convívio social devido às implicações decorrentes do horário de trabalho, associadas à sonolência constante e irritabilidade. 
Além disso, o enfermeiro que exerce sua função laboral nesse turno trabalha contra $\circ$ relógio biológico interno, fato este que interfere de forma direta e negativa no envolvimento destes profissionais com familiares e amigos, na execução das tarefas domésticas e outras mais simples que fazem parte do cotidiano destas pessoas.

Por outro lado, um estudo evidenciou aspectos positivos relacionados a metodologia do processo de enfermagem realizado no período noturno. Neste sentido, observa-se que o trabalho assistencial realizado nesse turno respectivamente é com melhor qualidade devido ao fato do enfermeiro ter maior acesso aos prontuários e exames, o que permite uma visão mais holística do paciente ${ }^{4}$.

Um aspecto relevante desse turno de trabalho confrontando com o período diurno referente ao profissional enfermeiro seria uma menor rotatividade de pessoas nos setores. Tal fato facilita a atuação destes profissionais devido até mesmo a própria dinâmica de cuidados que é de menor intensidade durante a noite.

Os enfermeiros que trabalham no período noturno exercem atividades que estão baseadas em técnicas mais complexas, focando na coordenação e supervisão da assistência de enfermagem, controle e apoio da equipe de enfermagem, assim como procedimentos privativos do enfermeiro ${ }^{4}$.

Ao trabalhar no período noturno, o enfermeiro lida com a questão de flexibilidade de horários, o que Ihe possibilita um duplo vínculo empregatício. Os enfermeiros também consideram o trabalho noturno mais produtivo do que o diurno, por uma série de questões que também envolvem maior atenção aos pacientes e familiares ${ }^{4}$.

Diante dos pressupostos observados, percebe-se que apesar de algumas peculiaridades o trabalho noturno do enfermeiro tem suas vantagens $e$ facilitadores do serviço que conferem a estes profissionais uma melhor adaptação ao turno de trabalho e consequentemente assistência prestada de qualidade aos pacientes.

\section{CONSIDERAÇÕES FINAIS}

O estudo demonstra que 0 trabalho noturno traz implicações na saúde geral do enfermeiro e alterações nas funções orgânicas destes profissionais. Entende-se que a inversão do ciclo sono-vigília constitui um fator determinante para o surgimento de inquietações psicológicas nos enfermeiros que atuam no período noturno e logo implica na dinâmica laboral com reflexos na qualidade da assistência prestada ao cliente.

No que se refere a organização do trabalho noturno, existem aspectos positivos embasados numa maior acessibilidade por parte do enfermeiro para com registros do paciente. Por outro lado, emergiram em maior proporção aspectos negativos que correlacionam sobrecarga de trabalho devido menor quantitativo de profissionais e relações interpessoais dificultadas devido a dinâmica de trabalho especificas de cada setor.

Além disso, tratando-se das relações familiares, o enfermeiro que trabalha no turno noturno sofre com o isolamento social por implicância do turno de trabalho. Possui a dificuldade de conciliar o horário da atividade laboral com o lazer e a família.

É fundamental pensar em estratégias que possibilitem aos trabalhadores noturnos melhores condições de trabalho. Vale salientar a necessidade da conscientização e o conhecimento das necessidades psicossociais desses profissionais, além de levar em consideração a qualidade de vida dos mesmos em seu ambiente de trabalho.

Desta forma, nota-se a importância de uma reflexão a cerca do assunto para alcançar uma melhora na situação de trabalho dos enfermeiros que exercem atividade no período noturno, valorização da categoria profissional e conseqüentemente retorno para população assistida em forma de cuidado com qualidade. 


\section{CONTRIBUIÇÕES DOS AUTORES}

Silva, AP participou da concepção, delineamento, busca dos dados da pesquisa, interpretação dos resultados, redação e encaminhamento do artigo científico. Carvalho, ES participou da concepção, delineamento, busca dos dados da pesquisa, interpretação dos resultados, redação do artigo científico. Cardim, A. participou da concepção, delineamento, interpretação dos resultados, redação do artigo científico

\section{CONFLITOS DE INTERESSES}

Nenhum conflito financeiro, legal ou político envolvendo terceiros (governo, empresas e fundações privadas, etc.) foi declarado para nenhum aspecto do trabalho submetido (incluindo mas não limitandose a subvenções e financiamentos, conselho consultivo, desenho de estudo, preparação de manuscrito, análise estatística, etc).

\section{REFERÊNCIAS}

1. Veiga KCG, Fernandes JD, Paiva MS. Análise fatorial de correspondência das representações sociais sobre o trabalho noturno da enfermeira. Rev Bras Enferm. 2013;66(1):18-24. doi: $10.1590 /$ S0034-71672013000100003

2. Santana RS, Brito BAM, Ferreira JLS, Silva AFL, Cunha MB, Viana LVM. Influência do trabalho noturno na qualidade de vida da equipe de enfermagem da UTI. Revista Interdisciplinar. 2015;8(2):25-34.

3. Silva RM, Beck CLC, Magnago TSBS, Carmagnani MIS, Tavares JP, Prestes FC. Trabalho noturno e a repercussão na saúde dos enfermeiros. Revista Esc Anna Nery. 2011 ; 15(2):270-76. doi: 10.1590/S1414$\underline{81452011000200008}$

4. Girondi JBR, Gelbcke FL. Percepção do enfermeiro sobre os efeitos do trabalho noturno em sua vida. Enfermagem em Foco. 2011 ;2(3):191-94. doi: 10.21675/2357-707X.2011. v2.n3.133

5. Conselho Federal de Enfermagem. Enfermagem em números. Quantitativo de profissionais por região [Internet]. 2016 [Acesso em 25 de julho de 2016]. Disponível em: http://www.cofen.gov.br/enfermagem-em-numeros

6. Bartoly DCC. Trabalho noturno em unidades fechadas: estudo com trabalhadores de enfermagem num hospital público [dissertação]. Rio de Janeiro: Centro Biomédico Faculdade de Enfermagem, Universidade do Estado do Rio de Janeiro; 2013.

7. Silveira M, Camponogara S, Beck CLC. As produções científicas sobre o trabalho noturno na enfermagem: uma revisão da literatura. J. res.: fundam. Care. Online. 2016;8(1):3679-90. doi: 10.9789/2175-5361.2016. v8i1.3679-3690
8. Palermo TAC, Rotenberg L, Zeitoune RCG, Silva-Costa A, Souto EP, Griep RH. Napping during the night shift and recovery after work among hospital nurses. Rev. Latino-Am. Enfermagem. 2015;23(1):1 14-121. doi: 10.1590/0104$\underline{1169.0147 .2532}$

9. Prodanov CC, Freitas EC. Metodologia do trabalho científico: Métodos e técnicas da pesquisa e do trabalho acadêmico. 2.ed. Novo Hamburgo: FEEVALE; 2013.

10. Xavier KGS, Vaguetti HH. Aspectos cronobiológicos do sono de enfermeiras de um hospital universitário. Rev Bras Enferm. 2012;65(1):135-40. doi: 10.1590/S003471672012000100020

11. Asaoka S, Aritake S, Komada Y, Ozaki A, Odagiri $Y$, Inove $S$ et al. Factors associated with shift work disorder in nurses working with rapid-rotation schedules in Japan: the nurses' sleep health project. Chronobiology International. 2013;30(4):628-36. doi: 10.3109/07420528.2012.762010

12. Anjum B, Verma NS, Tiwari S, Singh R, Mahdi AA, Singh $\mathrm{RB}$ et al. Association of salivary cortisol with chronomics of 24 hours ambulatory blood pressure/heart rate among night shift workers. BioScience Trends. 2011 ;5(4):182-88. doi: $\underline{10.5582 / \text { bst.2011.v5.4.182 }}$

13. Trinkoff $A M$, Johantgen $M$, Storr $C L$, Gurses $A P$, Liang $Y$, Han K. Nurses' work schedule characteristic, nurse staffing, and patient mortality. Nursing Research. 2011 ;60(1):1-8. doi: 10.1097/NNR.0b013e3181fff15d

14. Versa GLGS, Murassaki ACY, Inoue KC, Melo WA, Faller, JW, Matsuda LM. Estresse ocupacional: avaliação de enfermeiros intensivistas que atuam no período noturno. Revista Gaúcha Enfermagem. 2012;33(2):78-85. doi: $10.1590 /$ S1983-14472012000200012

15. Tsai Y-C, Liu C-H. Factors and symptoms associated with work stress and health-promoting lifestyles among hospital staff: a pilot study in Taiwan. BMC Health Services Research. 2012;12:199. doi: 10.1186/1472-6963-12-199

16. Dall'ora C, Griffiths P, Ball J, Simon M, Aiken LH. Association of $12 \mathrm{~h}$ shifts and nurses' job satisfaction, burnout and intention to leave: findings from a cross-sectional study of 12 European countries. BMJ Open. 2015;5:e008331. doi: 10.1136/bmiopen-2015-008331

17. Heponiemi T, Kouvonen A, Sinervo T, Elovainio M. Do psychosocial factors moderate the association of fixedterm employment with work interference with family and sleeping problems in registered nurses: a cross-sectional questionnaire survey. International Journal of Nursing Studies. 2010;47(9):1096-1 104. doi: 10.1016/i.ijnurstu.2010.01.008 